\title{
Effects of Leadership on Employee Morale in Higher Education
}

\author{
Abdulkadir Noor \\ School of Management \\ Shinawatra University \\ BBD Building (Viphavadi, 197 Vibhavadi Rangsit Rd. \\ Khwaeng Samsen Nai, Khet Phaya Thai \\ Krung Thep Maha Nakhon 10400 \\ Dr. Fuangfa Ampornstira \\ Dean, School of Liberal Arts, Shinawatra University \\ BBD Building (Viphavadi, 197 Vibhavadi Rangsit Rd, Khwaeng \\ Samsen Nai, Khet Phaya Thai, Krung Thep Maha Nakhon 10400
}

\begin{abstract}
Key factors of institutional success are included morale of employees, high morale brings organizations into success path and low morale causes to failure. increase of performance, efficiency of the employee is result of high morale, if the employee is more satisfied with leader his/her morale will be positive otherwise the vice versa, performance of employee is dependent to his/her morale wither is high or low so that study explores effects of leadership on employee morale in higher education, semi structural interview has been employed to collect data from scholars with different backgrounds and experience in Bangkok-Thailand. Result of the study shows that morale is a mediating variable between leadership styles or practices and staff performance, if the leadership behavior is satisfied to staff the morale will be high which leads better performance.
\end{abstract}

Keywords: Employee Morale, Leadership, Higher Education

\section{Introduction}

Higher education institutions contributes the development of the society in different aspects of the life such as economics, education and health, it produces well scholars and knowledgeable leaders in the global so that running university operations, academic programs, managing academic and support staff needs to keep it practice of leadership skills to maintain a positive morale of the staff. Some times higher education institutions experience different challenges such as increasing competition, downsizing, shortage of staffing and budget reductions which may have effect on morale of the staff. Prior research on leadership has shown that how a leader acts and communicates with followers during very challenging periods can create the foundation for future trust in the leader (Kasper-Fuehrer and Ashkanasy, 2001) and impact on morale. Some time you observe that some people in the workplace backbiting the management as a result of leadership practices of the management, According to Schuler (2004), most people who experience low morale in the work environment blame management or their immediate supervisor for their leadershiprelated competencies such as communicating vision, energizing staff, demonstrating trust and loyalty, and developing teams. Attracting and retaining of skilled, knowledgeable and competence employee in the educational institutions is imperative for effective delivery of services Naris and Ukpere (2010).

It is observable that most of higher education institutions in the global face problems such shortage of skilled staff, higher workload, low salaries, higher academic- student ration and lack of involvement in decision making process, these problems affect quality of education service in higher institutions. Universities are established to address educational needs and the development of the society; the drivers of higher institutions are human as any other organizations they need to be motivated and developed so without management is not possible to utilize human efforts for the purpose of organizational objectives, it is the leader who guides employee and create a vision for them to benefit their efforts, it is the leader who gives them physiological satisfaction, motivate and establish human relationship for maximum utilization of resource this known leadership style.

\section{Literature Review}

McKnight, Ahmad and Schroeder (2001) has defined moral it as "the degree to which an employee feels good about his/her work and work environment". It is also described as a total satisfaction that employee stems from the job, the environment and the factors that make satisfaction of personal fulfilment. 
It stands and establishes the feelings and attitudes of employees as "self-confidence, optimism and positive mental attitude". Morale contributes the achievement and failure of the organization, it is emotional that can change upon the work environment and constitutes important factor of the organizational success, employees with high level of satisfaction devotes better commitment to stay longer for the organization. it is affected by leadership than the low level of management, high or low morale is affected by set of factors including leadership approaches for response of changes in the external and internal environment (Ngambi,2011)

Morale relates with productivity and the employee performance, an employee in high morale condition often pay better commitment and tends to stay organization perfectly then low morale employees, commitment and loyalty increases with the increase of positive morale of staff. Low morale is high cost for the organization. Millett (2010) suggested six reason for the importance of morale, improvement of productivity, performance and creativity, decrease leave days, give attention to details, provide safety at the workplace and develop quality of the work. Mazin (2010), furthered that employee with high morale motivates people to come workplace on time, better communication, and not west the time for gossip, better improvement for recruitment and retention as well as more creativity. Several studies described that employee with low level of morale increases cost, absenteeism, strikes lack of motivation and interest, it can cause some time objection for the implementation of duties or service as effects the overall productivity of organization.

Many reasons contribute or cause low more for employees, the important considered to be poor leadership in organization as literature shows. Fretwell (2002) give importance to the role of leader because organizations are subject for the influence of leader's vision decision. Poor leadership contribute the causing factor to the low morale of employees (Schuler, 2004). Robbins (2003) also stressed that change and poor leadership are the main the low morale of employees. The negative factors that lowers employee morale are included leadership not acting or serving as a role model, little accountability and ignoring succession plan, organizational culture also effects employee morale (Stevens,2009).Lack of cooperation with management and poor relationship with coworkers and inflexible working environment make employees disappointed and lowers employee morale (Dye \& Garman, 2006).

Give employees respect, develop work conditions, skills and consider employee life environment as whole, these are part of approaches to handle and improve better morale of employee on instantiation and its leadership. Unsatisfiable leadership practices as decision making on small bodies or team, termination of skilled staff and reduction of budget creates state of employee stress and fear for their future in the institution. Leader is to be in the position to create environment of mutual trust among employees and leader which leads improves high level of employees as Dye and Garman (2006) suggested that accessibility of the manager, culture of openness and being role model for employees can give them can increase morale of employees. It is a leading by example and better communication with employees. Stevens (2009) gives five solutions to deal with low morale he stated that managers should attract the appropriate talent, and hiring for skill and behavior, finding best practice and hiring for passion and focus on the customer.

Leader inspires employees, gives instructions and guidance to lead them for the achievement for the desired goals and outcomes, he initiates and motivate employees so they can strive hard on the accomplishment of the goal. Academic leaders should encourage, instigate, guide and lead the faculty members towards accomplishment of common objective. Gmelch, W. H. (2002) academic leader is to work with his team as a group and guide them by giving instructions to each member about how to carry out and complete the work as he is to empower staff to come up with the desired result and achieve objectives. The maintenance of professional and providing autonomy to employees is considered important leadership quality (Brymans,2007), in such situation the leader should be strong to make faculty members satisfied and lead them attainment of the academic goals. The concept of Academic Leadership has been presented by Ramsden (1998) and he propose that leadership in higher education have characteristics as; leadership in teaching i.e. introducing new ideas of teaching, adding excitement teaching, leadership in research i.e. leader must set his own research examples and give guidance for the staff, strategy vision and networking i.e. leader should establish clear goals and articulate those to everyone, collaborative and motivational leadership i.e. leader should motivate people to give their full and try to achieve difficult objectives also there should be openness and an environment of trust and support, fair and efficient management i.e. delegating task and organize the tasks, development and recognition of performance i.e. praise people work and provide them with feedback and give them support, interpersonal skills i.e. look into other people's interests.

\section{Methodology}

The study explores and investigates the effects of leadership on employee morale using a descriptive approach and semi-structured interviews for the collection of the research data. To illustrate descriptive type of research, Bushman will guide the researchers when he stated: descriptive method of research is to gather information about the present existing condition. 
The purpose of employing this method is to describe the nature of a situation, as it exists at the time of the study and to explore the effects of particular phenomena on the performance of employees and firm, twenty of academic staff with different backgrounds and experience has been interviewed in April 2017. To conduct the interview the available academic staff invited for interview and gave them a specified appointment for time and place of interview, a professional digital voice recorder (IC RECORDER) used to record interview. Content analyse is used to examine the interview and draw conclusions regarding relationship between research variables in this study. Content analysis is a method of analyzing written, verbal or visual communication messages (Cole 1988). Content analysis as a research method is a systematic and objective means of describing and quantifying phenomena (Krippendorff 1980, DowneWamboldt 1992, Sandelowski 1995).

\section{Findings}

Regarding interview results morale of academic staff is associated with leadership practices and the academic environment, according to the interview results there are direct relations between leadership and the morale of the staff so that this relationship can determine the level of productivity and performance of the staff.

Three primary themes and sub themes has been identified to figure out relations between leadership behavior, morale and performance of the academic staff in higher education. The findings shows that leadership practices in academic environment can be participative and Autocratic according to the interview result each one has its own sub features explaining the effects and relations carry to the staff and the working environment, for example participative leadership allows joint decision making, were staff have input to the decision on particular issue, there is also good team work, opportunity for staff to demonstrate their skills and talents, leader presents opportunity for staff development and motivated to better performance through motivation, collaboration and team work so that the morale and performance of academic staff will be better. It is also demonstrates second sub theme Autocratic leadership, this type of leadership has more about bureaucracy and hierarchical structure, he is always center of all decision other staff implement decision no participation in decision making is allowed, staff work as per instructions given by the leader while academic environment is characterized by discussion, some of qualified academic staff may resign as result of demoralization emanating from practices and behavior of the leader, another consequences are included increase of absenteeism, decrease level of performance and productivity, increase of turnover rate, decrease of efficiency, all these are negative consequences caused by negative behavior of the leader.

\section{Conclusion}

This study confirmed that participative approach of leadership is effective in academic environment it will create collective responsibility and team work; in this approach staff will get an opportunity to exercise ideas and creativity they also get opportunity for professional development. This approach is known different name such as power sharing, management by objective, joint decision making and empowerment. Thrash, (2012) shown in the paper of "Leadership in Higher Education". Study also confirmed strong relationship between leadership behavior, morale and staff performance, leadership behavior in this study describe as independent variable, Morale described as mediating variable and performance as dependent variable. Leadership behavior whether is positive or negative it has direct relations or effect to the morale of the staff, if behavior of leader is negative first morale of staff suffers, staff feel dissatisfied and demoralized which leads poor performance in the working environment so that performance is dependent to the morale and leadership behavior.

\section{References}

McKnight, D. H., Ahmad, S. and Schroeder, R. G. (2001). When do feedback, incentive control and autonomy improve morale? The importance of employee management relationship closeness. Journal of Managerial Issues, 13(4), 466- 482.

Seroka J (2009). Boosting employee morale needs to occur daily, not only during times of crisis. Available: http://www.hrtools.com/insights [2010, May, 20].

Ngambi, H. C. (2011). The relationship between leadership and employee morale in higher education. African Journal of Business Management, 5(3), 762-776.

Millett T (2010). 6 reasons why staff morale is important. Available: http://EzineArticles.com [2010, May, 20].

Mazin R (2010). The effects of high morale on employee performance. Available: http://www.ehow.com [2010, May, 20].

Fretwell, J. B. (2002). Promoting Organizational Competency: A solution to increasing employee morale and customer satisfaction. Retrieved fromhttp://www.ceresinnovations.com/tools.htm.

Schuler AD (2004). Turning around low morale. Available: www.schulersolutions.com. [2010, May, 19]. 
Robbins NR (2003). Ideas for Invigorating morale in higher education. CUPA-HR J. 54(2): 19-21.

Stevens D (2009). The five causes of low employee morale-and how to avoid them. Available: http://www.humanresourcesiq.com [2010, May, 19].

Dye CF, Garman AN (2006). Exceptional leadership: 16 critical competencies for health care executives. Health Admin. Press. Chicago.

Gmelch, W. H. (2002). "The call for department leaders". New York: Paper presented at the Annual Meeting of the American Association of Colleges for Teacher Education.

Bryman, A. (2007). Effective leadership in higher education: a literature review. Studies in Higher Education, 32 (6), 693-710.

Kasper-Fuehrer E, Ashkanasy NM (2001). Communicating trustworthiness and building trust in interorganizational virtual organizations. J. Manage., 27(3): 235-254.

Naris NS, Ukpere IW (2010). Developing a retention strategy for qualified staff at the Polytechnic of Namibia. Afr. J. Bus. Manage., 4(6): 1078-1084.

Thrash, A. (2012). Leadership in higher education. International Journal of Humanities and Social Science, 2(13), 1-12.

Cole F.L. (1988) Content analysis: process and application. Clinical Nurse Specialist 2(1), 53-57.

Krippendorff K. (1980) Content Analysis: An Introduction to its Methodology. Sage Publications, Newbury Park.

Downe-Wamboldt B. (1992) Content analysis: method, applications and issues. Health Care for Women International 13, 313-321.

Sandelowski M. (1995) Qualitative analysis: what it is and how to begin? Research in Nursing \& Health 18, 371-375. 